\title{
SOME NEW INEQUALITIES FOR CONVEX FUNCTIONS WITH APPLICATIONS IN NORMED SPACES
}

\author{
N. S. BARNeTt AND S. S. DRAGOMIR
}

Abstract. Some new inequalities for convex functions defined on convex subsets in linear spaces with applications for the $p$-mean absolute deviation of a sequence of vectors are given, in a normed linear space.

Mathematics subject classification (2000): 26D15, 46B05. deviation.

Key words and phrases: Convex functions, Jensen's inequality, normed linear spaces, $p$-mean absolute

\section{REFERENCES}

[1] S. S. DRAGOMIR, Bounds for the normalised Jensen functional, Bull. Austral. Math. Soc. 74(2006), 471-478.

[2] S. S. DRagomir, J. PeČarić And L. E. Persson, Properties of some functionals related to Jensen's inequality, Acta Math. Hungarica, 70(1-2) (1996), 129-143.

[3] C. P. Niculescu AND L.-E. Persson, Convex Functions and their Applications. A contemporary Approach. CMS Books in Mathematics/Ouvrages de Mathématiques de la SMC, 23. Springer, New York, 2006.

[4] J. Pečarić, F. Proschan and Y. L. Tong, Convex Functions, Partial Orderings, and Statistical Applications. Mathematics in Science and Engineering, 187. Academic Press, Inc., Boston, MA, 1992. 